
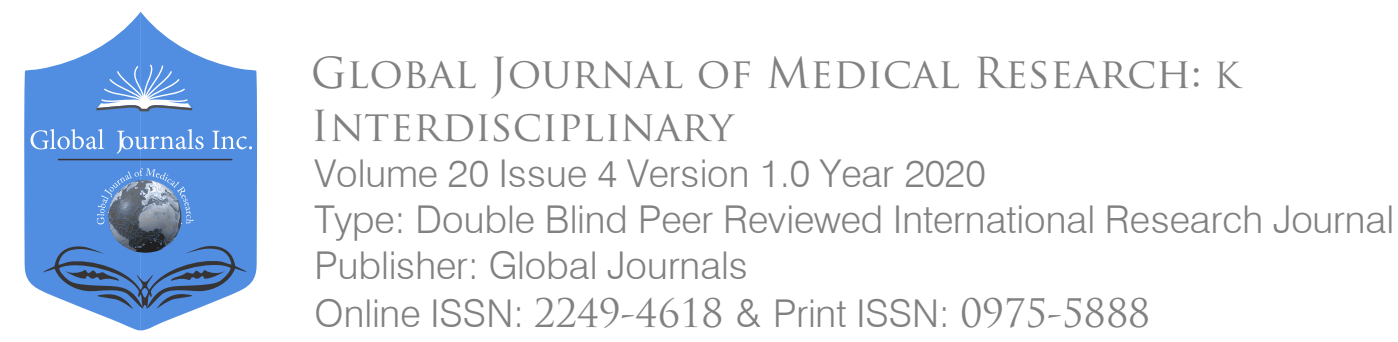

\title{
Odor Identification in Older Adults: Evidence from the Yakumo (2019)- Results by Gender and Age
}

By Naomi Katayama, Shoko Kondo, Satofumi Sugimoto, Tadao Yoshida, Masaaki Teranishi, Michihiko Sone, Yasushi Fujimoto, Hironao Otake, Hirokazu Suzuki, Takafumi Nakada, Naoki Saji, Seiichi Nakata \& Tsutomu Nakashima

Nagoya Women's University

Abstract- An examination of taste and olfactometry in Yakumo-Cho inhabitants' examination carried out in 2005, and the result reported in Academia Journal of Medicinal Plants 2018. This study examined olfactory function. A personal function test is calculated from the Yakumo study database, and the odor stick identification tests administered to healthy older adults. The participants were community dwellers who voluntarily participated in the Yakumo Study and had managed everyday life by themselves. The participants were engaged in a variety of jobs, not only white-collar but also agriculture, fishery, and forestry. Therefore, the city regarded as a representative of today's Japanese society. From the database, 298 participants (169 females and 129 males) were selected form data in August, 2019. The Odor Stick Identification Test (OSIT-J) was used to assess odor perception. The aromas used in the OSIT-J include curry, perfume, Japanese cypress, India ink, menthol, rose, wood, Smelly socks/ sweat, fried garlic, condensed milk, gas for cooking, and Japanese mandarin aromas.

Keywords: odor, threshold, odor stick identification test (OSIT-J), senior citizens, yakumo-study.

GJMR-K Classification: NLMC Code: WV 190

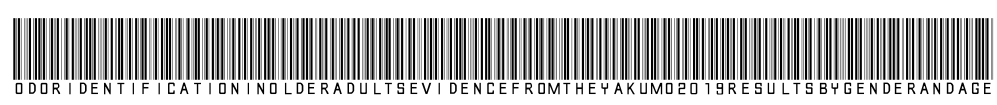

Strictly as per the compliance and regulations of:

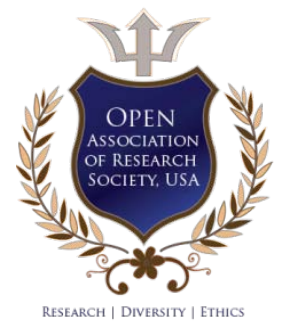

(c) 2020. Naomi Katayama, Shoko Kondo, Satofumi Sugimoto, Tadao Yoshida, Masaaki Teranishi, Michihiko Sone, Yasushi Fujimoto, Hironao Otake, Hirokazu Suzuki, Takafumi Nakada, Naoki Saji, Seiichi Nakata \& Tsutomu Nakashima. This is a research/review paper, distributed under the terms of the Creative Commons Attribution-Noncommercial 3.0 Unported License http://creativecommons.org/licenses/by-nc/3.0/), permitting all non-commercial use, distribution, and reproduction in any medium, provided the original work is properly cited. 


\title{
Odor Identification in Older Adults: Evidence from the Yakumo (2019)- Results by Gender and Age
}

\author{
Naomi Katayama ${ }^{\alpha}$, Shoko Kondo ${ }^{\sigma}$, Satofumi Sugimoto ${ }^{\circ}$, Tadao Yoshida ${ }^{\omega}$, Masaaki Teranishi ${ }^{*}$, \\ Michihiko Sone ${ }^{\S}$, Yasushi Fujimoto ${ }^{x}$, Hironao Otake ${ }^{\vee}$, Hirokazu Suzuki ${ }^{\ominus}$, Takafumi Nakada ${ }^{\zeta}$, Naoki Saji ${ }^{\ddagger}$, \\ Seiichi Nakata ${ }^{£}$ \& Tsutomu Nakashima ${ }^{\mathrm{F}}$
}

Abstract-An examination of taste and olfactometry in YakumoCho inhabitants' examination carried out in 2005, and the result reported in Academia Journal of Medicinal Plants 2018. This study examined olfactory function. A personal function test is calculated from the Yakumo study database, and the odor stick identification tests administered to healthy older adults. The participants were community dwellers who voluntarily participated in the Yakumo Study and had managed everyday life by themselves. The participants were engaged in a variety of jobs, not only white-collar but also agriculture, fishery, and forestry. Therefore, the city regarded as a representative of today's Japanese society. From the database, 298 participants (169 females and 129 males) were selected form data in August, 2019. The Odor Stick Identification Test (OSIT-J) was used to assess odor perception. The aromas used in the OSIT-J include curry, perfume, Japanese cypress, India ink, menthol, rose, wood, Smelly socks/ sweat, fried garlic, condensed milk, gas for cooking, and Japanese mandarin aromas. Each fragrance enclosed in microcapsules made of melamine resin. However, the olfactory test result was better for females. The reason is that 11 males out of 129 male participants (8.5\%) and two females of 169 female participants (1.2\%) had abnormal values in olfactory test results. Of the 12 odor, Fried garlic, Smelly socks/ sweat, and Curry recognized by more than $80 \%$. But, of the 12 odor, Rose, Wood, India Ink, and Household gas were by less than $60 \%$. Household gas was the most cognitively different odor between males and females, with males being $22.3 \%$ less cognitive than females. As olfactory decay is closely related to dementia, such as Alzheimer's disease. It is necessary to do that be increase the number of cases in the future. And it is also need to investigate the relationship between lifestyle and eating habits in the future.

Keywords: odor, threshold, odor stick identification test (OSIT-J), senior citizens, yakumo-study.

Corresponding author a: Nagoya Women's University, Nagoya City, 4678610, Japan.e-mail: naomik@nagoya-wu.ac.jp

Author $\sigma$ a: Graduate School of Nagoya Women's University, Nagoya City, Japan.

Author $\alpha \rho \omega ¥ \S \chi \vee F$ : Department of Otorhinolaryngology, Nagoya University Graduate School of Medicine, Nagoya, Japan.

Author v: Department of Sleep Medicine, Nagoya University Graduate School of Medicine, Nagoya, Japan.

Author $\theta \zeta \mathrm{fF}$ : National Center for Geriatrics and Gerontology, Obu, Japan.

Author $€$ : Department of Otolaryngology, Second HospitalFujita Health University School of Medicine, Nagoya, Japan.

Author F: Ichinomiya Medical Treatment and Habilitation Center, Ichinomiya, Japan.

\section{INTRODUCTION}

I he Japanese Government uses a large amount of funds for the care of elderly individuals because of a super-aged society. The elderly individual may have a decline in the sense of smell. There is a concern that with increasing age, individuals would soon be unable to identify through the sense of smell. Furthermore, nasal congestion and olfactory disorders occurring after inflammation that is caused by allergic rhinitis, modern-day hay fever, and colds also inhibit the sense of smell ${ }^{1,2,3)}$.

The odor of food is intimately related where our appreciating palate formed by a combination of olfaction (olfactory sense) and gustation (gustatory sense). Such a combination of smell and taste is referred to as 'flavor' and is an element in the appreciation of food.

Signals passing through the olfactory bulb travel to the brain along these olfactory nerves, where the signals interpreted, and the smell is recognized ${ }^{4)}$. The medial aspect of the temporal lobe that remembers smell also stimulated at this point, and the brain can identify the odor based on a memory of previously experienced smells. In other words, smell identification requires an already-accumulated set of experienced smells $s^{5,6)}$.

Both olfaction and gustation start to decline in humans around the age of 50 to 59 , with $40 \%$ of the elderly experiencing a noticeable the decline ${ }^{7)}$. A person's first awareness of decline in olfaction as our primary dependence for identification of flavor occurs when one is unable to distinguish food by taste alone.

Olfaction also performs an important and essential role in our ability to detect dangers, including the smell of leaking gas, the burning odor of fire, and the putrid smell of rotten food. Olfaction is also responsible for the enrichment and psychological stimulation in our everyday lives, such as with the scents and smells of foods and flavors ${ }^{8}$. In an already aged society, healthy olfaction is a necessary part of creating a safe and fertile living environment and for improving an individual's quality of life. 
This study aims to understand the age-related decline in olfactory function in participants aged 40 to 49 years, 50 to 59 years, 60 to 69 years, 70 to 79 years, and 80 to 89 years. We identified the odors particularly to distinguish for individuals of these age groups. This resultmight help draw attention to issues faced by individuals in their daily lives and facilitate improvement in their quality of life. Our previous paper ${ }^{9}$ reported that: the olfactory test result was better for females. The reason is that 27 males out of 190 male participants (14.2\%) and 16 females of 260 female participants (6.2\%) had abnormal values in olfactory test results.

Furthermore, in this study, when 12 kinds of odors is examined individually, it was revealed that some smells were easy to recognize, and some were difficult todo.

\section{Materials and Methods}

\section{a) Participants}

The participants were community dwellers who voluntarily participated in the Yakumo Study and had

Table 1: Age composition of participants in Yakumo inhabitants examination $(\mathrm{n}=298)$.

\begin{tabular}{lccccc}
\hline Participants & 40 's & 50 's & 60 's & 70's & 80's \\
\hline Male (129) & 10 & 24 & 49 & 40 & 6 \\
Female (169) & 23 & 40 & 66 & 37 & 3 \\
Total (298) & 33 & 64 & 115 & 77 & 9 \\
\hline
\end{tabular}

b) Assessment of odour identification

The Odor Stick Identification Test (OSIT-J) was used to assess odour perception. This test possesses high reliability and validity ${ }^{10)}$. The OSIT-J includes 12 different odorants to be identified. As odor perception is not necessarily culture-free, the Japanese version was employed ${ }^{11,12)}$. The procedure resembles that of the San Diego Odor Identification Test ${ }^{13)}$. The aromas used in the OSIT-J include curry, perfume, Japanese cypress, India ink, menthol, rose, wood, smelly socks / and sweat, roasted garlic, condensed milk, gas for cooking, and Japanese mandarin aromas. Each fragrance enclosed in microcapsules made of melamine resin. These microcapsules were mixed with an odorless solid cream and then shaped to look like a lipstick. During the inspection test, the examiner applied each odorant to a piece of paraffin paper. After the application, the examiner handed the paper to the participant, who would then sniff the one and identify the odor. Participants selected each answer from a set of cards, each of which listed the name of an odorant, including the correct answer. Each correct answer scored as one point with the total performance score ranging from 0 to 12 points. We defined it as follows: normal range as more than 6 , borderline as 3 to 5 , and abnormal as less than 2 points. All of these methods are the same as in the previously reported paper ${ }^{9}$. managed their everyday life themselves. The Yakumo Study conducted since 1981 as a joint project between the town of Yakumo in Hokkaido and the Nagoya University Graduate School of Medicine. Professionals in the fields of epidemiology, internal medicine, orthopedics, neuropsychology, ophthalmology, otolaryngology, and urology joined the Yakumo Study. The analyzed data were based on the database from 2019 to the neuropsychology and otolaryngology teams. The participants had been engaged in a variety of jobs, not only white-collar but also agriculture, fishery, and forestry. Therefore, this town can regarded as representative of today's Japanese society. From the database, 298participants (169 females and 129 males) were selected form data in August 2019 (Table 1). c) Questionnaire survey on cognitive odor perception

A direct questionnaire survey conducted on subjective odor perception. Participants chose their odor perception from three choices: well recognized, recognized, and unrecognized. The results tabulated.

\section{d) Ethical review board}

This study conducted with the approval of the Ethical Review Board (Nagoya women's university Ethics Committee: 'hitowomochiitakennkyuunikansuruiinnkai'). The approval number is 30-14.

\section{RESULTS}

\section{a) Questionnaire survey on cognitive odor perception}

Tabel 2. Shows, Ten males (7.8\%), and two females (1.2\%) answered that they could not perceive odor well. Males do not recognized it six times as strong as females. More than $90 \%$ of males and females, subjective odor was recognizable.

\section{b) Assessment of odor identification}

Olfactometry performed using odorstick (Diichiyakuhin Co. Ltd) ${ }^{14}$. However, the olfactory test result was better for females. Table 3 shows, it is as a result of the fact that 11 males out of 129 male participants (8.5\%) and two females of 169 female participants $(1.2 \%)$ had abnormal values in olfactory test results. 
Table 2: Results of Questionnaire Survey on subjective olfaction at Yakumo Tow Resident's medical examination Age $\cdot$ Sex distribution (number of participants: $(\%))(n=298)$

\begin{tabular}{|c|c|c|c|c|c|c|}
\hline & \multicolumn{3}{|c|}{ Male $\quad(n=129)$} & \multicolumn{3}{|c|}{ Female $(n=169)$} \\
\hline & Well Recognized & Recognizid & Unrecognizable & Well Recognized & Recognizid & Unrecognizable \\
\hline 40's（M=10, F=23） & $4(40.0 \%)$ & $6(60.0 \%)$ & $0(0.0 \%)$ & $8(34.8 \%)$ & $14(60.9 \%)$ & $1(4.3 \%)$ \\
\hline 50 's $(M=24, F=40)$ & $6(25.0 \%)$ & $16(66.7 \%)$ & $2(8.7 \%)$ & $17(42.5 \%)$ & $22(55.0 \%)$ & $1(2.5 \%)$ \\
\hline 60 's（M=49, $\mathrm{F}=66)$ & $17(34.7 \%)$ & $28(57.1 \%)$ & $4(8.2 \%)$ & $14(21.2 \%)$ & $52(78.8 \%)$ & $0(0.0 \%)$ \\
\hline 70's（M=40, $F=37 ）$ & $12(30.0 \%)$ & $25(62.5 \%)$ & $3(7.5 \%)$ & $22(59.5 \%)$ & $15(40.5 \%)$ & $0(0.0 \%)$ \\
\hline 80 's $(M=6, F=3)$ & 2 (33.3\%) & $3(50.0 \%)$ & $1(16.7 \%)$ & $1(33.3 \%)$ & $2(66.7 \%)$ & $0(0.0 \%)$ \\
\hline Total $(M=129, F=169)$ & ) $41(31.8 \%)$ & $78(60.5 \%)$ & $10(7.8 \%)$ & $62(36.7 \%)$ & $105(62.1 \%)$ & $2(1.2 \%)$ \\
\hline
\end{tabular}

Twelve odors examined individually. The results gas undrestood by less than $60 \%$. Household gas was shown in Tables 4 and 5. Of the 12 smells, Fried garlic, Smelly socks/ sweat, and Curry recognized by more than $80 \%$. But, Rose, Wood, India Ink, and Household the most cognitively different odor between males and females, with males being $22.3 \%$ less cognitive than females.

Table 3: Cognitive number results from 12 simple olfactory tests Age/sex distribution (number of participants) $(n=298)$

\begin{tabular}{|c|c|c|c|c|c|c|c|c|c|c|c|c|c|c|}
\hline \multirow[b]{2}{*}{ Male $(n=129)$} & \multicolumn{14}{|c|}{ Recognized number of odors types Male } \\
\hline & zero & one & two & three & four & five & six & seven & eight & nine & ten & eleven & twelve & Detection only \\
\hline 40 's $(n=10)$ & 0 & 0 & 0 & 0 & 0 & 0 & 1 & 2 & 1 & 2 & 1 & 2 & 1 & 0 \\
\hline 50 's $(n=24)$ & 0 & 0 & 0 & 1 & 1 & 2 & 2 & 0 & 4 & 7 & 6 & 1 & 0 & 0 \\
\hline 60's $(n=49)$ & 0 & 0 & 0 & 2 & 4 & 7 & 4 & 9 & 7 & 2 & 6 & 3 & 1 & 4 \\
\hline 70 's $(n=40)$ & 1 & 2 & 1 & 3 & 4 & 5 & 4 & 0 & 5 & 5 & 2 & 3 & 2 & 3 \\
\hline \multirow[t]{2}{*}{80 's $(n=6)$} & 0 & 1 & 0 & 0 & 0 & 2 & 1 & 0 & 1 & 1 & 0 & 0 & 0 & 0 \\
\hline & \multicolumn{14}{|c|}{ Recognized number of odors types } \\
\hline Female $(n=169)$ & zero & one & two & three & four & five & six & seven & eight & nine & ten & eleven & twelve & Detection only \\
\hline 40 's $(n=24)$ & 0 & 0 & 0 & 1 & 0 & 1 & 0 & 0 & 7 & 4 & 5 & 4 & 2 & 0 \\
\hline 50 's $(n=39)$ & 0 & 0 & 0 & 0 & 0 & 1 & 1 & 1 & 6 & 7 & 7 & 12 & 4 & 0 \\
\hline 60 's $(n=66)$ & 0 & 0 & 1 & 0 & 4 & 0 & 6 & 5 & 10 & 8 & 9 & 17 & 6 & 0 \\
\hline 70 's $(n=37)$ & 0 & 0 & 1 & 1 & 1 & 6 & 4 & 2 & 8 & 7 & 6 & 1 & 0 & 0 \\
\hline 80 's $(n=3)$ & 0 & 0 & 0 & 0 & 1 & 0 & 0 & 1 & 1 & 0 & 0 & 0 & 0 & 0 \\
\hline
\end{tabular}

Table 4: Results of 12 kinds of odor recognition test with odor stick (Number of participants) ( $n=298: 129$ male, 169 female)

\begin{tabular}{|c|c|c|c|c|c|c|c|c|c|c|c|c|c|}
\hline & Judgment & India ink & Wood & Perfume & Menthol & Orange & Curry & Household gas & Rose & Cypress & Smelly socks, and sweat & Condensed milk & Fried garlic \\
\hline \multirow{4}{*}{$\begin{array}{c}\text { Total } \\
(\mathrm{n}=298 \\
)\end{array}$} & mistake & 83 & 50 & 76 & 32 & 69 & 27 & 102 & 66 & 79 & 46 & 67 & 39 \\
\hline & Cognition & 162 & 176 & 193 & 218 & 188 & 239 & 174 & 141 & 182 & 239 & 210 & 242 \\
\hline & ditection & 45 & 56 & 24 & 39 & 39 & 25 & 22 & 70 & 29 & 12 & 19 & 17 \\
\hline & odorless & 8 & 16 & 5 & 9 & 2 & 7 & 0 & 21 & 8 & 1 & 2 & 0 \\
\hline \multirow{4}{*}{$\begin{array}{c}\text { Female } \\
(\mathrm{N}=169)\end{array}$} & mistake & 46 & 23 & 37 & 15 & 30 & 13 & 45 & 33 & 40 & 23 & 31 & 18 \\
\hline & Cognition & 108 & 111 & 124 & 135 & 117 & 142 & 115 & 94 & 115 & 144 & 131 & 147 \\
\hline & ditection & 13 & 25 & 7 & 4 & 21 & 10 & 9 & 30 & 12 & 2 & 6 & 4 \\
\hline & odorless & 2 & 10 & 1 & 4 & 1 & 4 & 0 & 12 & 2 & 0 & 1 & 0 \\
\hline \multirow{4}{*}{$\begin{array}{c}\text { Male } \\
(\mathrm{N}=129)\end{array}$} & mistake & 37 & 27 & 39 & 17 & 39 & 14 & 57 & 33 & 39 & 23 & 36 & 21 \\
\hline & Cognition & 54 & 65 & 69 & 83 & 71 & 97 & 59 & 47 & 67 & 95 & 79 & 95 \\
\hline & ditection & 32 & 31 & 17 & 24 & 18 & 15 & 13 & 40 & 17 & 10 & 13 & 13 \\
\hline & odorless & 6 & 6 & 4 & 5 & 1 & 3 & 0 & 9 & 6 & 1 & 1 & 0 \\
\hline
\end{tabular}

Table 5: Results of 12 kinds of odor recognition test with odor stick (\%) ( $\mathrm{n}=298: 129$ male, 169 female)

\begin{tabular}{|c|c|c|c|c|c|c|c|c|c|c|c|c|c|}
\hline & Judgment & India ink & Wood & Perfume & Menthol & Orange & Curry & Household gas & Rose & Cypress & Smelly socks, and sweat & Condensed milk & Fried garlic \\
\hline \multirow{4}{*}{$\begin{array}{c}\text { Total } \\
(\mathrm{n}=298 \\
)\end{array}$} & mistake & 27.9 & 16.8 & 25.5 & 10.7 & 23.2 & 9.1 & 34.2 & 22.1 & 26.5 & 15.4 & 22.5 & 13.1 \\
\hline & Cognition & 54.4 & 59.1 & 64.8 & 73.2 & 63.1 & 80.2 & 58.4 & 47.3 & 61.1 & 80.2 & 70.5 & 81.2 \\
\hline & ditection & 15.1 & 18.8 & 8.1 & 13.1 & 13.1 & 8.4 & 7.4 & 23.5 & 9.7 & 4.0 & 6.4 & 5.7 \\
\hline & odorless & 2.7 & 5.4 & 1.7 & 3.0 & 0.7 & 2.3 & 0.0 & 7.0 & 2.7 & 0.3 & 0.7 & 0.0 \\
\hline \multirow{4}{*}{$\begin{array}{c}\text { Female } \\
(\mathrm{N}=169)\end{array}$} & mistake & 27.2 & 13.6 & 21.9 & 8.9 & 17.8 & 7.7 & 26.6 & 19.5 & 23.7 & 13.6 & 18.3 & 10.7 \\
\hline & Cognition & 63.9 & 65.7 & 73.4 & 79.9 & 69.2 & 84.0 & 68.0 & 55.6 & 68.0 & 85.2 & 77.5 & 87.0 \\
\hline & ditection & 7.7 & 14.8 & 4.1 & 2.4 & 12.4 & 5.9 & 5.3 & 17.8 & 7.1 & 1.2 & 3.6 & 2.4 \\
\hline & odorless & 1.2 & 5.9 & 0.6 & 2.4 & 0.6 & 2.4 & 0.0 & 7.1 & 1.2 & 0.0 & 0.6 & 0.0 \\
\hline \multirow{4}{*}{$\begin{array}{c}\text { Male } \\
(\mathrm{N}=129)\end{array}$} & mistake & 28.7 & 20.9 & 30.2 & 13.2 & 30.2 & 10.9 & 44.2 & 25.6 & 30.2 & 17.8 & 27.9 & 16.3 \\
\hline & Cognition & 41.9 & 50.4 & 53.5 & 64.3 & 55.0 & 75.2 & 45.7 & 36.4 & 51.9 & 73.6 & 61.2 & 73.6 \\
\hline & ditection & 24.8 & 24.0 & 13.2 & 18.6 & 14.0 & 11.6 & 10.1 & 31.0 & 13.2 & 7.8 & 10.1 & 10.1 \\
\hline & odorless & 4.7 & 4.7 & 3.1 & 3.9 & 0.8 & 2.3 & 0.0 & 7.0 & 4.7 & 0.8 & 0.8 & 0.0 \\
\hline
\end{tabular}


Next, we examined the recognition of 12 kinds of odors by age and sex for each one. The results shown in Table 6 and Table 7. In this study, there were few participants in their 40's and 80's, so we compared males, and females in their 50's, 60's and 70's. Almost all odors were poorly recognized in both males and females in their 60's than in their 50's. Especially the male fried garlic was $24.5 \%$ worse. Also, in females, it had a $35,3 \%$ worse household gas in their 60's than in their 50's. It found that the odor suddenly became unrecognizable from the ' 60 s.

Table 6: Individual results for 12 types of odor tests age $\cdot$ sex distribution (number of participants)

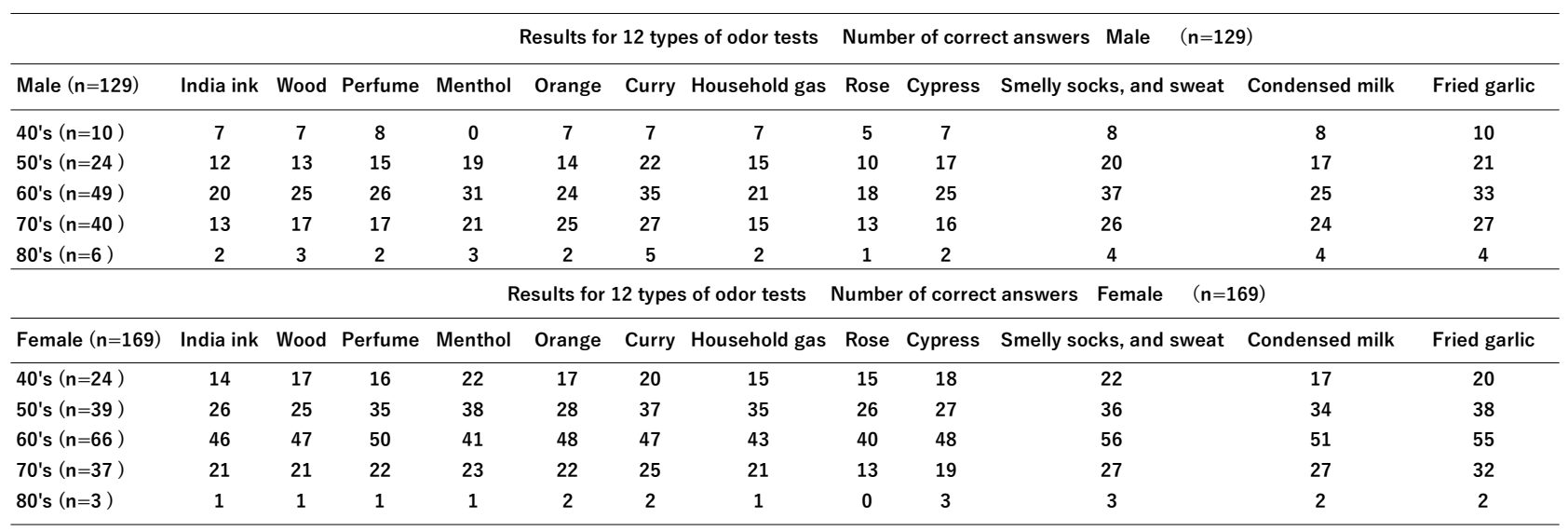

Table 7: Individual results for 12 types of odor tests age $\cdot$ sex distribution (\%)

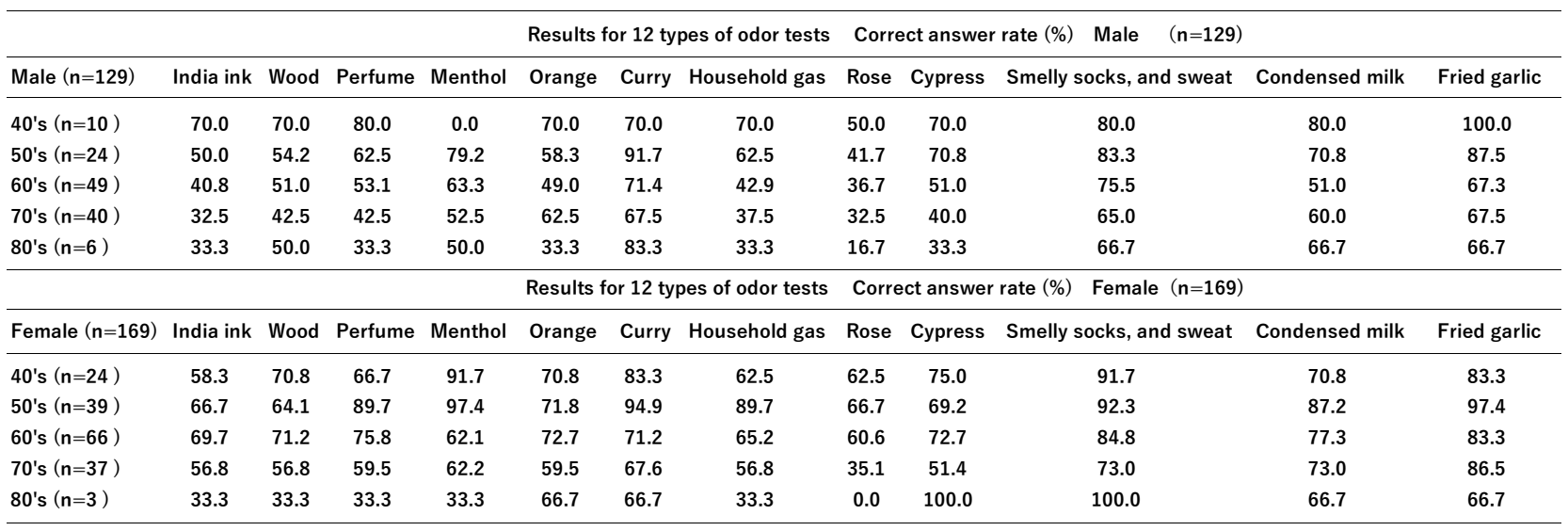

\section{Discussion}

It showed that the number of participants who show abnormal values in the olfactory test result is more than twice that of males as compared with females. This result was almost the same as the previous paper ${ }^{9}$. Also, as before, it was shown that the olfactory test results worsened as the age increased. Since olfactory test results have been reported by many researchers to be related to dementia such as Alzheimer's disease ${ }^{15}$. It is necessary to further investigate the number of cases in the future. Especially since males have poor olfactory test results as compared with females, this showed in the previous paper; it is necessary to investigate the relationship with lifestyle and eating habits in the future. Recently, it has reported that when a person suffers from COVID-19, he/she cannot sense the smell due to olfactory disorder ${ }^{16)}$. Research on olfaction will become more and more necessary in the future.
Twelve odors examined individually. The results are shown, of the 12 odors, Fried garlic, Smelly socks/ sweat, and Curry were recognized by more than $80 \%$. But, of the 12 smells, Rose, Wood, India Ink, and Household gas were understood by less than $60 \%$. Household gas was the most cognitively different odor between males and females, with males being 22.3\% less cognitive than females. It was a good result for both males and females to be familiar with curry that eats well in life, fried garlic with a burnt smell, and Smelly socks/ sweat that helps prevent food poisoning. However, it is that household gas is difficult to understand. This is because the odor must be instantly applied to aboid the danger of gas poisoning and gas explosion.

Next, we examined the recognition of 12 kinds of odors by age and sex for each one. The results are shown, in this study, there were few participants in their 40 's and 80's, so we compared males and females in 
their 50's, 60's, and 70's. Almost all odors were poorly recognized in both males and females in their 60's than in their 50 's. Especially the male fried garlic was $24.5 \%$ worse. Also, in females, it had a 35,3\% worse household gas in their 60's than in their 50's. It found that the odor suddenly became unrecognizable from the 60's. Since the perception of odors in participants in their 60's deteriorates sharply compared to those in their 50's. We believe that it is necessary to undergo a regular odor check after the '60s.

Moreover, the number of cases is small in the age of '80s in each one statistically processed at this time. Therefore, the result of this study does not go out of the range of the hypothesis. It is a future task as same as before.

\section{Conclusions}

In Yakumo Study, from the database, 298 participants (169 females and 129 males) were selected form data in August 2019. The aromas used in the OSIT$J$ include curry, perfume, Japanese cypress, India ink, menthol, rose, wood, Smelly socks/ sweat, fried garlic, condensed milk, gas for cooking, and Japanese mandarin aromas. The olfactory test result was better for females. The reason is that 11 males out of 129 male participants (8.5\%) and two females of 169 female participants (1.2\%) had abnormal values in olfactory test results. Of the 12 odors, Fried garlic, Smelly socks/ sweat, and Curry recognized by more than $80 \%$. But, of the 12 smells, Rose, Wood, India Ink, and Household gas understood by less than $60 \%$. Household gas was the most cognitively different odor between males and females, with males being $22.3 \%$ less cognitive than females.Almost all smells were poorly recognized in both males and females in their 60's than in their 50's. As olfactory decay is closely related to dementia such as Alzheimer's disease. It is necessary to that increase the number of cases in the future. Recently, it reported that when a person suffers from COVID-19, he/she cannot sense the smell due to olfactory disorder. We believe that regular olfaction testing is necessary to maintain the health of the elderly. And it is need to investigate the relationship between lifestyle and eating habits in the future.

\section{ACKNOWLedgements}

This study was supported by the research aid of Choju-iryo-kenkyu-kaihatsuhi 30-14 and the Japanese Society of Taste Technology, 2019.

\section{References Références Referencias}

1. Quint C, Temmel FA, Schickinger B et al (2001). Patterns of non-conductive olfactory disorders in eastern Austria; A study of 120 patients from the Department of Otorhinolaryngology at the University of Vienna. Wien Klin Wochenschr. pp.52-57
2. Welge-Lussen A, Wolfensberger M (2007). Olfactory disorders following upper respiratory tract infections; Taste and smell; Au update. Hummel T, Welge-Lussen A (eds),. Karger AG, Basel. Adv. Otorhinolaryngol. 63: 125-132

3. Kallmann JF, Schonfeld AW, Barrera ES (1944). The genetic aspects of primary eunuchoidism. Am. J. Ment. Defic. 48: 203-236.

4. Mori K, Takahashi YK, Igarashi KM, Yamaguchi M (2006). Maps of odourant molecular featuresin the mammalian olfactory bulb. Physiol. Pev. 86(2): 409-433.

5. Serizawa S, Ishii T, Nakatani $H$, Tsuboi A, Nagawa F, Asano M, Sudo K, Sakagami J, Sakano H, Ijiri T, Matsuda $Y$, Suzuki M, Yamamori T, Iwakura $Y$, Sakano H (2000). Mutually exclusive expression of an odorant receptor gene in YAC transgenic mice. Nat. Neurosci. 3(7): 687-693.

6. Serizawa S, Miyamichi K, Sakano H (2004). One neuron-one receptor rule in the mouse olfactory system. Trends Genet. 20(12):648-653.

7. Doty RL, Shaman P, Applebaum SL, Giberson R, Siksorski L, Rosenberg L (1983). Smell identification ability; Changes with age. Science. 226(4681): 1441-1443.

8. Saito S, Ayabe-Kanamura S, Takashima Y, Gotow N, Naito N, Nozawa T, Mise M, Deguchi Y, Kobayakawa $\mathrm{T}$ (2006). Development of a smell identification test using a novel stick-type odor presentation kit. Chem. Senses. 31(14):370-391.

9. Katayama N, Kondo S, Ootake H et al (2018). Odour and Salt Taste Identification in Older Adults: Evidence from the Yakumo Study in August, 2018. Acade. J. Med. Plants 7(3) 066-071.

10. Kobayashi M (2005). The odor Stick Identification Test for the Japanese (OSIT-J): Clinical suitability for patients suffering from olfactory disturbance. Chemical Senses, 30(Suppl 1): i216-i217.

11. Kobayashi M, Saito S, Kobayakawa T, Deguchi $Y$, Costanzo RM (2006). Cross-cultural comparison of data using the Odor Stick Identification Test for Japanese (OSIT-J). Chem. Senses. 31(4): 335-342.

12. Kobayashi M, Reiter ER, DiNardo JL, Costanzo MR (2007). A new clinical olfactory function test: cultural influence. Arch. Otolaryngol-Head Neck Surg. 133(4): 331-336.

13. Murphy C, Anderson AJ, Markinson S (1994). Psychophysical assessment of chemosensory disorders in clinical populations. In K. Kurihara, N. Suzuki, \& H. Ogawa (Eds.) Olfaction and Taste. Tokyo: Springer Verlag Tokyo. pp. 609-613

14. Ayabe-Kanamura S, Sachiko S, Yasuhiro T, Gotow N, Naomi N, Takashi N, Miyako M, Yuichi D, Tatsu K (2005). Development of a smell identification test using a novel stick-type odor presentation kit: The 
generation and a sex factor. J. Aroma Sci. Technol. 31(4):52-55.

15. Jimbo D, Kimura Y, Taniguchi M, Inoue M, Urakami $\mathrm{K}$ (2009). Effect of aromatherapy on patients with Alzheimer's isease. Psychogeriatrics. 9(4): 173-179.

16. Jean-Francois Gautier, Yann Ravussin (2020). A New Symptom of COVID-19: Loss of Taste and Smell. Ovesity 28(5): 848 